\title{
PROEDES - Programa de Estudos e Documentação Educação e Sociedade: origens e desenvolvimento
}

\author{
PROEDES - Program of Studies and Documentation Education and Society: \\ origins and development \\ PROEDES - Programa de Estudios y Documentación Educación y Sociedad: \\ orígenes y desarrollo
}

MARIA DE LOURDES DE ALBUQUERQUE FÁVERO

Universidade Federal do Rio de Janeiro.

Resumo: $\mathrm{O}$ artigo apresenta a experiência da construção coletiva do PROEDES, na Faculdade de Educação da Universidade Federal do Rio de Janeiro, no período de 1987 a 2009. Situa o trabalho de investigação com o de resgate, recuperação e organização de fontes documentais, tornando-as acessíveis e colocando-as em relação até constituírem um conjunto, por meio do qual a memória coletiva passa a ser valorizada, instituindo-se em patrimônio cultural e oferecendo importantes subsídios para estudos e investigações, em um espaço que se constituiu como efetivo centro de pesquisa e documentação em educação brasileira.

Palavras-chave: Proedes; Documentação; Educação e Sociedade; Memória e Patrimônio Cultural.

Abstract: The article presents the experience of the collective construction of Proedes, at the Faculty of Education of the Federal University of Rio de Janeiro, from 1987 to 2009. It situates the research work with the rescue, recovery, and organization of documentary sources, making them accessible and placing them in relation until they constitute a set, through which the collective memory starts to be valued, establishing itself in cultural heritage and offering important subsidies for studies and investigations, in a space that became an effective research center and documentation on Brazilian education.

Keywords: Proedes. Documentation, Education and Society. Memory and Cultural Heritage.

Resumen: El articulo presenta la experiencia de la construcción colectiva de PROEDES, en la Facultad de Educación de la Universidad Federal de Rio de Janeiro, de 1987 a 2009. Sitúa el trabajo de investigación en el rescate, recuperación y organización de fuentes documentales, haciéndolos accesibles y ubicándolos en relación hasta que constituyan un conjunto, a través del cual la memoria colectiva comienza a ser valorada, estableciéndose en el patrimonio cultural y ofreciendo importantes subsidios para estudios e investigaciones, en un espacio que se convirtió en un centro de investigación efectivo y documentación sobre educación brasileña.

Palabras clave: Proedes. Documentación, Educación y Sociedad, Memoria. Patrimonio Cultural. 


\section{DAS ORIGENS À CONSTRUÇÃO DO PROEDES}

No presente texto, apresentamos ${ }^{1}$, com base em estudos anteriores, a experiência do PROEDES, no período de janeiro de 1987 a junho de 2009, durante o qual fomos responsáveis por sua Coordenação. Sinalizaremos alguns desafios gerados em um espaço que se constituiu como um centro de pesquisa e documentação em educação brasileira numa universidade federal. Trata-se de articular o trabalho de investigação com o de resgate, recuperação e organização de fontes documentais, tornando-os pertinentes, colocando-os em relação, até constituírem um conjunto, por meio do qual a memória coletiva passa a ser valorizada, instituindo-se em patrimônio cultural, além de oferecer importantes subsídios para estudos e investigações de pesquisadores não apenas da UFRJ, mas também de outras instituições do Rio de Janeiro, do país e até mesmo do exterior.

O PROEDES tem sua origem no projeto de pesquisa "Da Faculdade Nacional de Filosofia à Faculdade de Educação: resgate de uma história", desenvolvido por um grupo de pesquisadores, com a participação de mestrandos e doutorandos, bem como de bolsistas de Iniciação Científica, Aperfeiçoamento e Apoio Técnico. Teve início em janeiro de 1987 e foi desenvolvido até julho de 1990, com o apoio do CNPq, da FAPERJ e da Fundação Universitária José Bonifácio (FUJB/UFRJ), além de importante colaboração e assessoria do Arquivo Nacional na organização do fundo da Faculdade Nacional de Filosofia.

Durante esse período, o trabalho do grupo de pesquisa centrou-se no levantamento e análise de dados relativos à Faculdade Nacional de Filosofia $(\mathrm{FNFi})$, procurando apreender as razões que contribuíram e influenciaram sua criação em 1939, seu desenvolvimento e sua fragmentação, efetuada entre 1967 e 1968. Extinta em 1968, a FNFi continua presente na memória daqueles que a produziram e vivenciaram, assim como nas unidades da UFRJ que nela têm suas origens: Escola de Comunicação, Faculdade de Educação, Faculdade de Letras, Instituto de Biologia, Instituto de Física, Instituto de Filosofia e Ciências Sociais, Instituto de História, Instituto de Geociências, Instituto de Matemática e Instituto de Química.

Com a preocupação de apreender melhor a história dessa Faculdade, realizamos não somente a análise de suas fontes documentais, como também procuramos ouvir pessoas que participaram e produziram a Faculdade Nacional de Filosofia: ex-professores, ex-alunos e ex-funcionários, realizando entrevistas, das quais trinta e oito estão publicadas no livro Faculdade Nacional de Filosofia:

1 Embora o artigo tenha uma autoria individual, o plural inserido pretende indicar o trabalho desenvolvido em conjunto com os pesquisadores, bolsistas, mestrandos e doutorandos, ao longo do período abordado. 
Depoimentos. UFRJ, 1992. Os demais depoimentos não incluídos nesse livro, porque não se dispunha na época de autorização dos entrevistados para sua divulgação, encontram-se no PROEDES, abertos à consulta.

Um problema grave e que não podemos deixar de registrar é que, até 03 de outubro de 1990, tínhamos um arquivo sonoro com cerca de cem fitas cassete gravadas, contendo entrevistas com ex-professores, ex-alunos e ex-funcionários da FNFi. Lamentavelmente, esse material foi furtado do prédio da Biblioteca do Centro de Filosofia e Ciências Humanas ( $\mathrm{CFCH})$, onde estava preservada parte da Biblioteca do CBPE/INEP e, naquele período, funcionava também o PROEDES. Embora a ocorrência tenha sido registrada na Secretaria de Estado da Polícia Civil do Rio de Janeiro, em 04 de outubro de 1990, não se obteve qualquer informação a respeito.

Não houve consequências maiores da perda dessas fitas, pois os depoimentos sobre a Faculdade Nacional de Filosofia estavam transcritos, e a maior parte autorizada para publicação pelos respectivos entrevistados. $\mathrm{Na}$ percepção dos que trabalhavam e continuam a fazê-lo no PROEDES, não somente a UFRJ perdeu parte de sua memória gravada, assim como parte da história da ciência no país. Tratava-se de um estudo que vínhamos desenvolvendo com especial interesse e com imensas dificuldades. Naquele momento, o apoio da Reitoria e do Decanato do CFCH da UFRJ foi providencial, como também o de alguns pesquisadores e cientistas de outras instituições, dentre os quais destacaríamos o professor José Leite Lopes, do Centro Brasileiro de Pesquisas Físicas (CBPF) e ex-catedrático da Faculdade Nacional de Filosofia.

Até então, não imaginávamos a possibilidade dessa ocorrência. Temíamos, sim, que essas fitas, por motivos diversos, viessem a ser danificadas. Por essa razão, e graças ao auxílio solicitado à FAPERJ, naquele ano, parte dos recursos seria destinada à aquisição de um lote considerável de fitas para se fazer duplicata de cada entrevista, a qual ficaria guardada em outro local, na UFRJ. Mas, o inesperado ocorreu.

Passados cerca de trinta anos, cabe assinalar que não somente chegamos a entender de forma mais clara o significado e a perda dessas importantes fontes, como às vezes tem ocorrido em arquivos e museus do país, mas também aprendemos que sempre é tempo de recomeçar. Após um problema dessa natureza, a equipe de pesquisa precisa ter muita clareza sobre o que pretende realizar, em que apostar e, especialmente, muita imaginação para prosseguir. Atendidas essas pré-condições, o trabalho não sofreu para encontrar uma solução de continuidade, procurando-se os entrevistados e solicitando a colaboração 
daqueles que ainda não tinham visto a transcrição de sua entrevista para fazer sua leitura e, se estivesse de acordo, autorizar a publicação, como também a abertura ao público para consultas. A resposta foi integralmente positiva.

Outra questão que precisa ser registrada é que, no início da pesquisa sobre a Faculdade Nacional de Filosofia, não tínhamos ideia precisa da situação em que se encontrava seu acervo. Para surpresa nossa e da equipe, deparamo-nos com grande quantidade de documentos sem nenhuma organização arquivística, muitos deles estragados, com perda de informações, outros acidificados pela falta de climatização, muitos danificados pela ferrugem de clipes e grampos, vários incompletos. Além disso, as entrevistas realizadas permitiram inferir que parte significativa de fontes documentais textuais foram destruídas ou desapareceram após o Golpe de 1964, quando militares passaram a "visitar" a Faculdade para obter informações. Entre os documentos desaparecidos, chamaram especial atenção os livros de Atas das Reuniões da Congregação referentes aos anos de 1962, 1963 e do primeiro semestre de 1964, jamais encontrados.

$\mathrm{O}$ acesso e o contato direto com as fontes documentais do arquivo nos deixaram perplexos em relação ao estado lamentável de conservação desse fundo, sobretudo por se tratar de um arquivo de grande relevância para o conhecimento mais completo da história da Universidade Federal do Rio de Janeiro (UFRJ), como também de instituições educacionais e científicas no país. O trabalho de recuperação e organização desse importante fundo, constituído atualmente por cerca de 110 mil documentos, nos fez ver, com maior clareza, que a preservação e a valorização da memória educacional e cultural brasileira era e continua sendo tarefa que está a desafiar permanentemente a intervenção lúcida e diligente das iniciativas públicas e particulares.

Ao mesmo tempo em que desenvolvíamos a pesquisa sobre a Faculdade Nacional de Filosofia e organizávamos seu acervo, as reflexões da equipe se ampliavam em dupla direção: de um lado, a necessidade de se definir um referencial teórico para melhor apreender a realidade, admitindo que a teoria é fundamental para se lidar com os fatos, para se dialogar com as fontes; de outro, a necessidade de criar um espaço que possibilitasse o diálogo teórico-metodológico, de forma consistente e consequente, com a clareza de que a produção científica não se faz isoladamente. Sob essa ótica, a opção assumida pelo grupo passou a ser a de ampliar o trabalho, o que nos levou, após vários debates em reuniões, a elaborar o Projeto de Estudos e Documentação Educação e Sociedade - PROEDES.

Em decorrência do trabalho realizado, o PROEDES foi aprovado em agosto de 1990 pelo Conselho de Ensino para Graduados (CEPG/UFRJ) como projeto integrado, tendo como principais objetivos: a) dar continuidade à pesquisa sobre a Faculdade Nacional de Filosofia e completar a organização de seu arquivo; 
b) desenvolver estudos e pesquisas sobre instituições educacionais e científicas no país e seus atores; c) organizar um centro de documentação e pesquisa referente à história da educação brasileira, às instituições educacionais e científicas no país e ao pensamento educacional brasileiro, sobretudo a partir de 1930. Com vistas à concretização desses objetivos, durante dois anos, demos continuidade à pesquisa sobre a Faculdade Nacional de Filosofia, procurando-se aprofundar as seguintes questões: quais foram concepções de ensino e pesquisa nos diferentes departamentos dessa Faculdade e como essas concepções se refletiram mais tarde em escolas, faculdades e institutos da UFRJ que tiveram origem naquela instituição.

Desde então, a ideia de se criar um núcleo, centro ou programa de estudos e documentação foi se tornando realidade, reforçada quando recebemos o Arquivo do Asylo de Meninos Desvalidos, em agosto de 1990, com cerca de 34 mil documentos. Trabalhando na organização desse Arquivo, recordamos um momento marcante quando lemos, pela primeira vez, uma carta de alforria manuscrita, datada de $1^{\circ}$ de março de 1878 , escrita pela Baronesa de Guanabara, cujo teor é o seguinte:

Pela presente carta de alforria, por mim escripta e assignada, concedo liberdade à minha escrava Cyprianna que possuo por título de compra, feita pelo meu finado marido, e que me tocou nas partilhas, a que se procedeu por morte do mesmo; e faço esta concessão gratuitamente, atenta aos bons serviços que dita escrava tem prestado; pelo que d'ora em diante poderá dispor de si livremente, como se de ventre livre houvesse nascido e completamente isenta de qualquer obrigação.

A leitura desse documento, assim como de outros que se encontram nesse arquivo, deixam evidente que o escravo era "uma mercadoria", "um bem", nas mãos dos senhores de engenho, de fazendeiros, dos donos do poder político e econômico do país, o que, no contexto da mentalidade da época, era encarado como um comportamento socialmente aceito.

A partir de 1991, o PROEDES, expandiu-se com a doação de arquivos e coleções de diversos educadores: Durmeval Trigueiro Mendes, João Roberto Moreira, Raul Bittencourt, Paschoal Lemme, importantes documentos de Anísio Teixeira e várias coleções temáticas, abrangendo documentos relativos aos Acordos MEC-USAID, à Constituinte de 1988, à Lei de Diretrizes e Bases da Educação Nacional de 1996, além de outros.

Nesse contexto, havia da parte daqueles que integravam o Projeto de Estudos e Documentação a preocupação de não apenas resgatar, recuperar e organizar as fontes documentais, procurando articulá-las, de modo que a memória coletiva educacional fosse valorizada e preservada, mas também de 
desenvolver pesquisas. Os pesquisadores tinham presente a importância dessas fontes documentais para o estudo da história da educação brasileira, da história de instituições educacionais e científicas do país, bem como do pensamento educacional brasileiro.

Após vários contatos com diferentes instâncias decisórias da UFRJ, em 1994 o Projeto foi reconhecido como Programa pela Congregação da Faculdade de Educação em 1995, pelo Conselho de Coordenação do Centro de Filosofia e Ciências Humanas (CFCH) e pelo Conselho de Ensino para Graduados (CEPG) da UFRJ.

Com essa nova identidade, o Programa de Estudos e Documentação Educação e Sociedade redefiniu seus objetivos: a) realizar estudos e pesquisas referentes a temas de educação, a instituições educacionais e científicas; b) contribuir para a formação de pesquisadores; c) constituir-se em um centro de documentação em educação brasileira.

Para concretizar esses objetivos, o PROEDES passou a desenvolver estudos e investigações em duas linhas de pesquisa. A primeira, centrada na história das instituições educacionais e científicas no país, com os seguintes propósitos: a) estudar essas instituições, buscando identificar as propostas e as condições que deram origem à sua criação, institucionalização e desenvolvimento; b) analisar o papel, as contribuições e a importância estratégica de instituições educacionais e científicas nos embates políticos e ideológicos que se travaram no país, em especial no período que se estende de 1930 aos dias atuais, procurando caracterizar, também, suas relações de poder, mecanismos de dominação e participação, bem como sua constituição e funcionamento; c) investigar contribuições inovadoras de instituições educacionais, em termos de concepção de ensino, pesquisa e extensão universitária, propostas curriculares, formação de professores e especialistas em diferentes áreas do conhecimento, assim como pesquisadores e de administradores de educação.

A segunda linha, centrada na construção do pensamento educacional brasileiro, passou a ter as seguintes diretrizes: a) investigar o processo de construção desse pensamento, identificando suas origens, matrizes e formas como se traduz na história da educação brasileira, por seus pressupostos políticos, a legislação, planos e programas educacionais; b) analisar o pensamento de educadores brasileiros, sua trajetória e produção acadêmico-científica, como também a contribuição prestada à educação no país; c) analisar ideias, planos e propostas adotadas pelo sistema educacional, sobretudo a partir dos anos 1930, por meio de órgãos governamentais, instituições de ensino público e privado. 
Nessa perspectiva, graças ao esforço e à dedicação daqueles que se empenharam em seus projetos e vinham trabalhando no PROEDES, este espaço de pesquisa e documentação foi gradativamente sendo reconhecido como Centro de Referência em Educação Brasileira, no qual eram e são oferecidas informações sobre a história da educação brasileira, as instituições educacionais e científicas no país e sobre o pensamento educacional brasileiro. Possibilita àqueles que o procuram não apenas a consulta ao acervo documental que está sob a sua guarda, mas também orientação para busca de referências em outros órgãos de documentação e pesquisa existentes no Rio de Janeiro. Assim sendo, em benefício dos que consultam o PROEDES, procuramos interagir com outros centros de documentação e bibliotecas: Arquivo Nacional, Biblioteca Nacional, Arquivo da Cidade do Rio de Janeiro, CPDOC/FGV e outros, encaminhando pesquisadores que buscam informações e dados para seus estudos e pesquisas.

\section{O PROEDES: produzindo referências em educação}

Como decorrência dessa caminhada, a partir da pesquisa sobre a Faculdade Nacional de Filosofia e a organização de seu acervo, junto a outros arquivos e coleções, enquanto Centro de Estudos e Documentação, o PROEDES abriga atualmente um acervo constituído por cerca de 400 mil documentos, distribuídos em arquivos e coleções.

A preocupação com o trabalho, a pesquisa e a divulgação de informações contidas nos acervos que estão sob a guarda desse Programa revela, também, a necessidade de assegurar a um centro de documentação como este seu papel de agência de apoio e referência à pesquisa, além da tarefa de viabilizar as possibilidades de acesso, organização e preservação de fontes documentais. Sob esse ponto de vista, o trabalho com arquivos e coleções existentes nos tem levado a perceber, cada vez com maior clareza, que se o documento é ponto de partida para se conhecer um fato histórico. É também por meio dele que podemos revisitar o passado e reinterpretá-lo sob novo olhar, como observa Le Goff:

O documento não é inócuo. É antes de mais nada o resultado de uma montagem, consciente ou inconsciente da história, da época, da sociedade que o produziram, mas também das épocas sucessivas durante as quais continuou a viver, talvez esquecido, durante as quais continuou a ser manipulado, ainda que pelo silêncio (1992, p. 547). 
Daí, "ser preciso começar por desmontar, demolir esta montagem, desestruturar esta construção e analisar as condições de produção dos documentos / monumentos" (idem, p. 548). Nessa perspectiva, endossamos Margarida de Souza Neves, quando afirma:

O historiador não é um arqueólogo da documentação, mediador neutro entre a verdade da fonte e a verdade da História, mas aquele sim que é capaz de formular uma problemática e de construir uma interpretação em que reconhece o encontro entre duas historicidades: a sua própria e a da documentação que utiliza (1985, p. 34-35).

Apoiando-nos nessas percepções, acreditamos que o trabalho com as fontes documentais existentes no PROEDES nos permitiram compreender que a exploração dessas fontes é de fundamental importância, à medida em que esses documentos oferecem elementos para análises e abordagens diferenciadas no processo de elaboração do conhecimento em história da educação brasileira, história social e política da cultura, história das instituições educacionais e científicas no país e sobre o pensamento educacional brasileiro.

Todavia, consideramos que os fatos e os dados não falam por si. Como observa Carr, falam apenas quando o historiador os aborda, procurando apreender o pensamento que está por trás deles. É o historiador "quem decide quais os fatos e os documentos que vêm à cena e em que ordem ou contexto" (1978, p.14).

Observamos, por outro lado, que a experiência possibilita a compreensão de que a integração do pesquisador com as fontes constitui um diálogo permanente entre o passado e o presente; embora jamais se consiga conhecer a totalidade do caminho. A busca de um conhecimento consistente se apresenta como uma relação permanente e esclarecedora entre fragmentos documentais e o todo que se devem elucidar mutuamente. O PROEDES tem como uma de suas preocupações produzir referências em educação, levantar questões que se colocam e que poderão levar a outros desafios. No entanto, faz-se necessário considerar que é no contato com a realidade que se pode "corrigir" uma percepção falha e capacitar-se para melhor reconstruí-la.

Para apresentar uma visão mais abrangente do Programa de Estudos e Documentação Educação e Sociedade como um espaço que produz conhecimento em educação, parece-nos necessário situar não apenas os aspectos interiores dessa construção, de um ponto de vista estritamente epistemológico, mas também chamar a atenção para aspectos que buscam entendê-lo no seu tempo e na instituição que o abriga. 
Nessa perspectiva, é oportuno indicar estudos e pesquisas desenvolvidos pelos pesquisadores, pós-graduandos, bolsistas de Iniciação Científica, Aperfeiçoamento e Apoio Técnico integrados ao Programa. Vale mencionar ainda os acervos que estão sob sua guarda, nos quais se encontram trabalhos sobre a história das instituições educacionais e científicas e temas relacionados à educação, assim como ao pensamento educacional brasileiro.

Indicaremos alguns dos produtos que marcaram sua história e contribuíram para dar visibilidade ao trabalho desenvolvido neste espaço, como um centro de estudos, pesquisa e documentação. Começamos pelo projeto $\mathrm{Da}$ Faculdade Nacional de Filosofia à Faculdade de Educação: resgate de uma história, coordenado por mim, com a participação das pesquisadoras: Eloisa Guimarães, Lúcia Maria França Siano e Luciane Quintanilha Falcão, contando também, em momentos diferentes, com os pós-graduandos: João Eudes Pinheiro, Martha C. Salgado Bonardi, Ana Elisa Gerbasi de Almeida, Maria do Carmo de Lacerda Peixoto, Bárbara Gil Guedes.

Como resultado desse projeto, cinco dissertações de Mestrado foram elaboradas no Programa de Pós-Graduação em Educação da UFRJ: a) Martha C. Salgado Bonardi. Faculdade Nacional de Filosofia: um estudo da formação do professor secundário, defendida em 30/05/1990; b) Ana Elisa Gerbasi C. de Almeida. A Faculdade Nacional de Filosofia e a Criação de Instituições Científicas: o caso do Centro Brasileiro de Pesquisas Físicas, defendida em 21/05/1992; c) Mônica Caminiti Ron-Rén. Faculdade Nacional de Filosofia: das propostas de fragmentação à extinção, defendida em 30/03/1994; d) Nadja Paraense dos Santos. Da Faculdade Nacional de Filosofia à criação do Instituto de Química da Universidade Federal do Rio de Janeiro, defendida em 29/03/1994; e) Ana Lúcia Cunha Fernandes. A Representação e a Participação Estudantil na Faculdade Nacional de Filosofia na Década de Sessenta, defendida em 11/01/1996.

Foi publicada ainda uma série de estudos, constituída de cinco volumes sobre a FNFi: V.1 - Faculdade Nacional de Filosofia. Projeto ou trama universitária? Rio de Janeiro: Editora UFRJ; INEP, 1989, 99 p; V.2 - Faculdade Nacional de Filosofia. O Corpo Docente. Matizes de uma proposta autoritária. Rio de Janeiro. Editora UFRJ; INEP, 1989, 136 p.; V.3 - Faculdade Nacional de Filosofia. Caminhos e descaminhos. Rio de Janeiro. Editora UFRJ; INEP, 1989, 85 p.; V.4 - Faculdade Nacional de Filosofia. Os Cursos: começando a desenrolar um novelo. Rio de Janeiro. Editora UFRJ; INEP, 1989, 79 p.; V.5 - Faculdade Nacional de Filosofia: Depoimentos. Rio de Janeiro: FUJB, CFCH, Faculdade de Educação e PROEDES /UFRJ, 1992, 542 p. Em caráter complementar, foi publicado em 1995, ano em que a UFRJ comemorava 75 anos de sua criação, o V.6 
da série: Catálogo do Arquivo da FNFi. Esse Catálogo indica um total de 89.248 documentos textuais, sendo 237 documentos visuais e três mapas hidrográficos referentes à construção de um pavilhão de Botânica por essa Faculdade em 1942.

Foram elaborados alguns trabalhos importantes dentro da linha de pesquisa Instituições Educacionais e Científicas e seus Atores, sob a nossa orientação, como dissertações de mestrado e teses de doutorado. Dissertações de Mestrado: a) Maria Thereza Pinto Ferreira. A Obrigatoriedade Escolar na Perspectiva dos Direitos Humanos, defesa 24/06/1982; b) Idalina de Meirelles Pinto. Nível de Integração entre as Escolas Tributárias e os Centros Interescolares da SME/RJ, defesa 28/06/1983; c) Helena Rosa Trope. Educação Artística: um estudo das escolas oficiais de $5^{a}$ à $8^{a}$ série do Município do Rio de Janeiro, defesa 04/05/1984; d) Elizabeth Jones. Professor de Pós-Graduação: Esboço para um Perfil do Intelectual Acadêmico, defendida em 13/08/1987; e) Maurício Pinheiro. A Autonomia e o Desempenho da Universidade, segundo Dirigentes Universitários, defendida em 24/09/1987; f) Virgínia Maria Nogueira de Vasconcellos. A Escola Nacional de Belas Artes: 1930-1945, defendida em 16/03/1994; g) Luiz Claudio dos Santos Ribeiro. A Ideologia da Excelência Acadêmica: um debate que se inicia, defendida em 11/09/1996. Teses de Doutorado: a) Janete Magalhães Carvalho. A Formação do Professor e do Pesquisador em Nível Superior no Brasil: análise histórica do discurso do governo e da comunidade acadêmico-científica (19451964), defendida em 23/03/1992; b) João Eudes Rodrigues Pinheiro.

O PREMEM no Espírito Santo: Educação, autoritarismo e tecnocracia. Subsídios para a História da Educação Capixaba, defendida em 28/04/1993; c) Maria do Carmo de Lacerda Peixoto. Escola de Pesquisar: estudo sobre a formação do pesquisador, defendida em 21/03/1994; d) Maria das Graças Medeiros Tavares. Extensão Universitária: novo paradigma de universidade?, defendida em 1996; e) Sylvia Garcia Rodrigues. O Colégio Universitário e a Reforma da Universidade Federal de Minas Gerais, defendida em 14/04/1997; f) Luiz Fernandes Dourado. Expansão e Interiorização do Ensino Superior em Goiás nos Anos 80: a política de privatização do público, defendida em 28/01/1997.

Dentro desse projeto maior, no período em análise, foram desenvolvidos no PROEDES outros 16 projetos de pesquisa, a saber:

1) O Currículo da Pós-Graduação em Educação da UFRJ: os dez primeiros anos, coordenado pelo professor Antônio Flávio Barbosa Moreira e iniciado em outubro de 1992, com apoio do CNPq. Como desdobramentos desse projeto, foram defendidas cinco dissertações de mestrado e uma tese de doutorado. As dissertações foram: a) Álvaro Chrispino - Didática Especial de Química e Prática de Ensino de Química: uma proposta voltada para a Química e a Sociedade (1992); b) Elizabeth Menezes Teixeira - A Ideologia do Feminino na 
Formação da/o Enfermeira/o (1995); c) Eduardo Grinspum Koatz - O Processo de Criação da Faculdade Nacional de Arquitetura e seu Currículo (1996); d) José Carlos Barbosa da Silva - As Percepções de Docentes e Egressos sobre o Curso de Licenciatura e Formação de Psicólogos da UNIR (1999); e) João P. Gonçalves de Assis - O Currículo de Educação Física da Universidade Federal do Acre: percepções dos egressos (1999). E a tese de doutorado: Isaura Setenta Porto O Sentido da Mudança e a Mudança do Sentido: História de uma Experiência Curricular na Graduação em Enfermagem (1997).

2) O Curso de Pedagogia da UFRJ visto pelos egressos (1979 a 1999), coordenado pela pesquisadora Helena Ibiapina Lima, de 1995 a 1999, contando com a colaboração de duas bolsistas de Iniciação Científica do CNPq e tendo como objetivo verificar até que ponto o Curso de Pedagogia contribuiu para a produção de novos conhecimentos e para a formação profissional de seus alunos. Dessa pesquisa, resultaram os artigos: a) Avaliação Institucional no Ensino Superior: uma perspectiva histórica. Revista IGLU. Sainte-Foy/Quebec/ Canadá, deuxième semestre, 1997, p.101; b) The University Integrated with Society: Pilot Experiment of an Undergraduate Course Evoluation. Cape Town/ South Africa: University of Cape Town (School of Education), 1998, p.67; c) O Curso de Pedagogia da UFRJ visto pelos egressos (1979/1994). Revista Educação Brasileira, Brasilia, v. 20, n. 40, $1^{\circ}$ semestre de 1998, p. 155-167; d) Capítulo de livro: "A Formação de Professor: questões atuais do Curso de Licenciatura"., de Helena Ibiapina Lima, Ruth da Cunha Pereira, Vera Maria Klöeter e Vera Vergara Esteves, publicado em: Wally Chan Pereira (Org.). Educação de professores na era da globalização: subsídios para uma proposta humanista. Rio de Janeiro: Editora Nau, 2000.

3) Acesso ao Ensino Superior: evolução, dilemas e perspectivas, desenvolvido a partir de 2000, pela pesquisadora Helena Ibiapina Lima, com o objetivo de estudar como se processou o acesso ao ensino superior no país, a partir de 1911, buscando: a) analisar dilemas surgidos ao longo desses anos, no que se refere ao exame de ingresso, conteúdo abrangido, nível de complexidade, função classificatória e validade de instrumentos para avaliar os níveis de escolarização anteriores; b) examinar mudanças introduzidas pela nova Lei de Diretrizes e Bases da Educação (Lei n. 9394/96), a legislação complementar e as normas do $\mathrm{CNE}$; c) verificar formas de acesso que contemplam o princípio de equidade de oportunidades, inclusive entre os que concluíram o ensino médio há mais tempo. Dessa pesquisa resultou o trabalho apresentado na XXIII Jornada de Iniciação Científica da UFRJ, ocasião em que bolsistas de Iniciação Científica, sob a orientação da pesquisadora, fizeram uma comunicação intitulada Acesso 
ao Ensino Superior: evolução, dilemas e perspectivas. Este trabalho obteve a primeira classificação entre os 301 trabalhos apresentados no Centro de Filosofia e Ciências Humanas (CFCH).

4) A UDF Revisitada, mar./1996 a fev./1998, tendo como objetivos: a) analisar o papel e a importância da UDF no contexto dos anos 1930; b) examinar convergências e divergências entre o projeto do Governo Federal para a universidade e a proposta da UDF, quanto à concepção de universidade, ensino e pesquisa e formação de professores; c) recuperar as contribuições inovadoras dessa universidade para as instituições universitárias no país. O projeto foi desenvolvido pelas pesquisadoras Maria de Lourdes de A. Favero e Maria do Carmo de Lacerda Peixoto (com bolsa de recém-doutor da FAPERJ), contando com a participação de Alice Ferry de Moraes, mestranda em Ciência da Informação, da Escola de Comunicação/UFRJ; Bolsistas de Iniciação Científica do CNPq: Adriana Lima Leitão, Tatiana Beaklini Moraes e Nísia Trindade; Bolsistas de Apoio Técnico do CNPq: Maurício Girão Plata, Suely Benedito da Rocha e Mônica Caminiti RonRén.

Como produção científica relacionada ao projeto, resultou: um capítulo de livro de Maria de Lourdes de A. Favero. "A UDF. Construção criadora e extinção autoritária." In: Morosini, Marília C. (Org.) A Universidade no Brasil: concepções e modelos. Brasília: INEP, 2006, p.53-70. Artigos publicados pela mesma autora: a) "A Universidade do Distrito Federal (1935-1939): uma utopia vetada?". Ciência Hoje, Rio de Janeiro. SBPC, v. 21, n. 125, p. 69-73, 1996; b) "Anísio Teixeira e a UDF: que lições nos oferecem?". Revista Brasileira de Política e Administração da Educação. Porto Alegre. ANPAE, v. 17, n.1, p. 87-101, jan./ jun.2001; c) "A UDF, sua vocação política e científica: um legado para se pensar a universidade hoje”. Revista Pro-Posições. Campinas, v.15, n.3, p. 143-162, 2004.

Em decorrência desse projeto, foram apresentados também sete trabalhos em congressos e encontros acadêmicos científicos: a) de Maria de Lourdes de A. Favero: "A Universidade do Distrito Federal: da construção criadora à extinção autoritária". In: X Seminário Nacional Universitas/Br; Educação Superior no Brasil em Mudança. Estado do Conhecimento. Teoria e Prática, 2005. Porto Alegre. Anais do X Seminário Nacional do Universitas/Br, 2005; b) "A Universidade do Distrito Federal (1935-1939). Centro de Estudos e de Produção do Saber". IV Congresso Luso-Afro-Brasileiro de Ciências Sociais, 1998. Rio de Janeiro. Anais do IV Congresso Luso-Afro-Brasileiro de Ciências Sociais. Rio de Janeiro: IFCS/UFRJ, 1996, p. 121-131; c) "A Universidade do Distrito Federal, Brasil: uma proposta fecunda”. I Congresso Luso-Brasileiro de História da Educação. 1996, Lisboa. Actas do I Congresso Luso-Brasileiro de História da Educação. Porto: Sociedade Portuguesa de Ciências da Educação, 
1996, v.1, p. 303-311; d) “A UDF: uma proposta vetada?”. 19a Reunião Anual da ANPEd. 1996. Caxambu/MG, p.1-15 (CD-Rom); e) "A Universidade do Distrito Federal, Brasil. Centro Vivo de Estudos e de Pensamento". Trabalho apresentado no III Congresso Iberoamericano de Historia de la Educación Latinoamericana. Caracas/Venezuela, 9 a 14 de julho de 1996. f) Adriana L. Ribeiro Leitão, Sônia Cristina Bernardino e Suely Benedito da Rocha Ribeiro: "A UDF - dos cursos e atividades acadêmicas". Trabalho apresentado na XVII Jornada de Iniciação Científica da UFRJ, de 6 a 9 de nov./1995; g) Tatiana Beaklini Moraes. "A UDF: o acesso e seus alunos". Trabalho apresentado na XVII Jornada de Iniciação Científica da UFRJ, 6 a 9 de nov./1995 e publicado com o mesmo título na Série Iniciação do PROEDES/FE/UFRJ, n. 005, Rio de Janeiro, novembro, 1996, 13 p.

Dessa linha, resultaram ainda três estudos publicados na Série Cadernos do PROEDES: a) Maria de Lourdes de A. Favero. A Universidade do Distrito Federal: 1935-1939. Centro de Estudos e de Produção do Saber, 1996; b) Maurício Girão Plata. Universidade do Distrito Federal: uma concepção conflitante de universidade, 1997; e c) Tatiana Beaklini Moraes. A UDF: o acesso e seus alunos,1997.

'É fundamental destacar que desse projeto resultou também a organização arquivística do acervo da Universidade do Distrito Federal (UDF), constituído por cerca de 5.500 documentos, que só foram preservados porque a Secretária Geral da Universidade, Odette Toledo, havia guardado em sua residência parte da documentação, depois que a UDF foi extinta no Estado Novo pelo Decreto $n^{\circ}$ 1.063 , de 20 de Janeiro de 1939, e seus cursos transferidos para a Universidade do Brasil.

5) Ensino com pesquisa: da utopia individual à realidade institucional, coordenado pela professora Stella Cecília Duarte Segenreich, desenvolvido de março de 1998 a fevereiro de 2000. Como outros projetos, também estava vinculado à linha de pesquisa História das Instituições Educacionais e Científicas no País. Desse projeto resultaram trabalhos apresentados em congressos pela pesquisadora: a) "A prática da pesquisa nas universidades emergentes x consolidadas: diferentes contextos compartilhando o mesmo problema" (ANPAE, 1998); b) "Relação ensino e pesquisa: políticas públicas e realidade institucional” (ANPAE, 2000). Cabe assinalar que o principal texto elaborado a partir dessa pesquisa foi "Relação ensino de graduação e pesquisa: políticas públicas e realidade institucional" publicado em 2001, no livro Educação Superior: análise e perspectivas de pesquisa, fruto da integração de seus resultados com os dados do Banco Universitas/Br, organizado por pesquisadores do GT Política de Educação Superior da ANPEd. 
6) Multiculturalismo e Educação: perspectivas internacionais e a experiência brasileira, coordenado pela professora Ana Canen (atualmente, Ana Ivenicki) e desenvolvido entre 1998 e 2001, com apoio do CNPq, tendo a pesquisadora produzido vários trabalhos: "Multiculturalismo e Formação Docente: Experiências Narradas" In: Educação e Realidade, v. 24, n.2, 1999; em co-autoria com o prof. Antônio Flávio B. Moreira. "Reflexões sobre o Multiculturalismo na Escola e na Formação Docente”. Revista Educação em Debate, ano 21, v.2, n.38, 1999; "Universos culturais e representações docentes: subsídios para formação de professores para a diversidade cultural". Revista Educação e Sociedade, n.77, Campinas, 2001; "Formação de Professores e Diversidade Cultural". In: Vera Maria Candau (Org.). Magistério:

Construção Cotidiana. Petrópolis: Editora Vozes, 1997; em coautoria com o prof. Antônio Flávio B. Moreira (Orgs.) Ênfases e Omissões no Currículo. São Paulo: Ed. Papirus, 2001. Entre as dissertações defendidas no Programa de Pós-Graduação em Educação/UFRJ, relacionadas a esse Projeto, destacam-se: "A Formação de Professores para uma Sociedade Multicultural", de Gisele P. Moura Xavier (2001); e "Reflexões Multiculturais no Processo Ensino-Aprendizagem da Matemática: intenções políticas e uma ação na sala de aula”, de Maria Inês Lavinas Pereira (2001).

7) A Universidade do Brasil: o grande projeto universitário, desenvolvido no período de março/1996 a fevereiro/2000, tendo como objetivos: a) aprofundar a discussão sobre a concepção de universidade que marcou a história dessa instituição, a partir de sua criação em 1920, passando pela Reforma Francisco Campos (Decretos no 19.851 e no 19.852 , de 11 de abril de 1931) e pela Lei no 452 , de 5 de julho de 1937, que a reorganiza denominando-se Universidade do Brasil (UB), até novembro de 1965, quando, em decorrência da Lei no 4.831/1965, recebe o nome de Universidade Federal do Rio de Janeiro (UFRJ); b) analisar como se expressa nessa instituição o princípio de autonomia universitária; c) examinar a composição e o papel dos órgãos colegiados nessa instituição; d) identificar as condições para o desenvolvimento do ensino, da pesquisa e extensão com vistas à produção do conhecimento nessa Universidade.

O projeto foi desenvolvido pelos pesquisadores: Maria de Lourdes de A. Favero e Jader de Medeiros Britto; bolsistas de Iniciação Científica: Adriana Coelho Valetim, Daniel de Farias Simões, Elaine Vieira Lacerda, Flávio Antônio de Souza França, Marco Aurélio S. Martins, Raul Machado Borges, Rosa Cristina C. Pinto, Sonia Cristina Bernardino Ribeiro e Tatiana Beaklini Moraes; bolsistas de Apoio Técnico: Maurício Girão Plata (mar./1996 a jan./1997) e Sandra Cristina Demétrio de Moraes. 
Como produtos dessa pesquisa foram publicados três livros: a) Maria de Lourdes de A. Favero. Universidade do Brasil: das origens à construção. Rio de Janeiro: Editora UFRJ/Comped/INEP, 2000, v. 1, 184 p., com prefácio do Professor Emérito da UFRJ José Leite Lopes. A $2^{a}$ edição revista e ampliada, com 200 p., foi lançada em 2010; b) Maria de Lourdes de A. Favero. Universidade do Brasil: guia dos dispositivos legais. Rio de Janeiro: Editora UFRJ/ Comped/ INEP, 2000, v. 2, 257 p.; c) Tatiana Beaklini Moraes. O Colégio Universitário da Universidade do Brasil: 1937 a 1942. Rio de Janeiro: Papel Virtual Editora, 2001. Este livro é resultado da dissertação de mestrado em educação defendida pela autora.

A pesquisa ofereceu ainda subsídios para duas monografias de conclusão do Curso de Bacharelado em História, do Departamento de História do IFCS/ UFRJ: a) Raul Machado Borges. Extensão Universitária: um estudo sobre a prática extensionista da Universidade do Rio de Janeiro à Universidade do Brasil (19311945). Rio de Janeiro, 1998; b) Flávio Antônio de Souza França. A Cátedra na Universidade do Brasil no Estado Novo, 1999. Com base nesta pesquisa foram apresentados trabalhos em congressos e encontros acadêmico-científicos: a) Maria de Lourdes de A. Favero. "Da Universidade do Brasil à UFRJ: um itinerário marcado de lutas", no II Luso-Brasileiro de História da Educação, realizado de 16 a 19 de fevereiro 1998, na Faculdade de Educação/USP; b) Maria de Lourdes de A. Favero. "Da Cátedra ao Departamento na Universidade do Brasil", na V Jornada de Pesquisadores em Ciências Humanas, CFCH/UFRJ, 25 a 27 de outubro de 1999; c) Tatiana Beaklini Moraes. "Universidade do Brasil: Poder e Cátedra nos Primeiros Anos (1937-1945)", na Jornada de Iniciação Científica /UFRJ, 1996; d) Raul Machado Borges. "A Universidade do Brasil: origens e caminhos (19201950)”, na XIX Jornada de Iniciação Científica da UFRJ.

A respeito da temática educação superior, foram elaborados, também, no período, os livros: a) A UNE em tempos de autoritarismo, de Maria de Lourdes de A. Favero. Rio de Janeiro: Editora UFRJ, 1995 e reeditado em 2009, com as orelhas do livro escritas pelo prof. Carlos Nelson Coutinho; b) Anísio Teixeira: educação e universidade (1999), organizado por Maria de Lourdes de A. Favero e Jader de Medeiros Britto e incluído nas obras completas desse educador, publicada pela Editora da UFRJ.

8) Doutores em Educação pela UFRJ: teses defendidas e vida profissional. A pesquisa foi desenvolvida pelas professoras Diana Couto Pinto e Lúcia Regina G. Vilarinho, tendo como objetivo analisar as teses produzidas no Doutorado em Educação da UFRJ, nos períodos de 1986 a 1990 e de 1991 a 1997, buscando estabelecer relações entre as teses produzidas, trabalhos acadêmicos delas derivados e a ocupação de cargos ou exercício de funções após a obtenção 
do título de doutor. Eram também objetivos do estudo: identificar as temáticas mais recorrentes; estabelecer sua vinculação às linhas de pesquisa e determinar os principais referenciais teóricos que fundamentaram a pesquisa, da qual resultou o trabalho intitulado "Um olhar sobre as teses do Curso de Doutorado em Educação da UFRJ: primeiras aproximações”, apresentado em 2000, na Jornada de Pesquisadores do CFCH/UFRJ.

9) Criadores e legitimadores de instituições educacionais no Brasil: suas ações e seus textos. O projeto foi desenvolvido no período de março de 2001 a fevereiro de 2003, coordenado pela professora Libânia Nacif Xavier, tendo como objetivo analisar a contribuição de Anísio Teixeira, Fernando de Azevedo, Jayme Abreu e João Roberto Moreira para a consolidação da pesquisa na área da educação no período de 1950 a 1960. Entre os resultados dessa investigação destaca-se o estudo: "Fernando de Azevedo e o legado de uma geração". In. Walter E. Garcia (Org.) Educadores Brasileiros do Século XX, Vol. I. Brasília, Plano Editora, 2002, p. 117-138.

10) O IESAE: construção, desenvolvimento e extinção, desenvolvido de março/2000 a fevereiro/2003, tendo como objetivos: a) analisar as origens e a construção do Instituto de Estudos Avançados em Educação - IESAE/FGV, de sua criação em 1971 até sua extinção em 1990, procurando compreender como se processou o ensino, a pesquisa e a produção acadêmica no Mestrado em Educação desse Instituto, bem como os Cursos de Especialização ministrados e a prestação de serviços como uma das formas de intercâmbio com outras instituições-educacionais e de pesquisa no país; b) examinar as razões que levaram a FGV a extinguir esse Instituto e consequentemente o Mestrado em Educação, apesar desse Mestrado ter recebido o Conceito A em sucessivas avaliações da CAPES.

O projeto foi realizado por Maria de Lourdes de A. Favero e o pesquisador Jader de Medeiros Britto, com a participação dos bolsistas de Iniciação Científica: Camila de Menezes Silva e Pablo Silva Machado Bispo dos Santos, além de uma bolsa de Apoio de Técnico à Claudia Araújo dos Santos Bayert. Contamos também com o apoio do CNPq, que concedeu uma bolsa de Produtividade em Pesquisa, duas bolsas de Iniciação Científica e uma de Apoio Técnico, além de recursos financeiros.

Como resultado da pesquisa obtivemos dois trabalhos apresentadas por Maria de Lourdes de A. Favero: a) "A experiência do IESAE/FGV: das origens à construção". 24 Reunião Anual da ANPEd, 2001. Caxambu/MG; b) "Um olhar sobre o IESAE através de fontes documentais". IV Congresso Luso-Brasileiro de História da Educação, 2002. Porto Alegre/RS. Obtivemos ainda quatro trabalhos apresentados pelos bolsistas nas Jornadas de Iniciação Científica da UFRJ (2000 
e 2001), o que valeu menção honrosa outorgada pela Universidade, em 2000, ao bolsista Pablo Silva Machado Bispo dos Santos, colocado entre os doze primeiros de toda Universidade e selecionado para apresentar em forma de pôster sob o título "O IESAE/FGV e a Revista Fórum Educacional: 1977 a 1990", na 53a Reunião Anual da SBPC, realizada em Salvador/Bahia, em julho de 2001. Merece registro também a organização arquivística do acervo desse Instituto, constituído por cerca de 3.000 documentos.

11) Estudos e Documentação, Educação e Sociedade, desenvolvido de ago./1990 a fev./1994, por Maria de Lourdes de A. Favero, como Coordenadora do PROEDES, com a colaboração das doutorandas Marluce Moura de Medeiros e Maria do Carmo de Lacerda Peixoto; dos mestrandos Luiz Carlos Barreto Lopes e Jucinato de Sequeira Marques e dos bolsistas de Iniciação Científica Flávio Antonio de Souza França e Ana Lúcia Badih Dawache. Esse projeto tinha por objetivos: a) dar continuidade à pesquisa sobre a Faculdade Nacional de Filosofia, analisando as concepções de ensino, pesquisa e extensão nos diferentes departamentos dessa Faculdade e como se manifestaram posteriormente nos institutos, faculdades e escolas que tiveram origem naquela instituição; b) processar a organização arquivística dos acervos: Asylo dos Meninos Desvalidos; coleções e arquivos pessoais de educadores, como os de Raul Bittencourt, João Roberto Moreira, Norma Cunha Osório, entre outros. Do trabalho com o Arquivo do Asylo de Meninos Desvalidos, orientados por Maria de Lourdes de A. Favero, resultaram duas dissertações de mestrado: a) Luiz Carlos Barreto Lopes. "Projeto Educacional Asylo de Meninos Desvalidos: Rio de Janeiro (1875-1884), uma contribuição à história social da educação no Brasil”, defendida em 30/03/1994; b) Jucinato de Sequeira Marques. "Os Desvalidos: o caso do Instituto Profissional Masculino (1894-1910): Uma Contribuição à História Social das Instituições Educacionais na Cidade do Rio de Janeiro”, defendida em 15/04/1996.

12) Campanha de Aperfeiçoamento e Difusão do Ensino Secundário (CADES): origens, caminhos e descaminhos. O projeto foi desenvolvido, de mar./1995 a fev./1997, pela pesquisadora Diana Couto Pinto, contando com apoio financeiro do CNPq. Os resultados parciais e final dessa pesquisa foram apresentados em congressos e encontros acadêmico-científicos. Alguns foram publicados em anais ou livro: a) Campanha de Aperfeiçoamento e Difusão do Ensino Secundário: origens, caminhos e descaminhos. 18a Reunião Anual da ANPEd, 1995, Caxambu/MG; b) CADES e ensino secundário: avanço ou retrocesso? 49a Reunião Anual da SBPC, 1997, Belo Horizonte. Anais da 49a Reunião Anual da SBPC, 1997, p.478-479; c) Campanha de Aperfeiçoamento e Difusão do Ensino Secundário: uma trajetória bem sucedida? I Congresso Brasileiro de História da Educação/2000, Rio de Janeiro. Educação no Brasil: 
história e historiografia. Rio de Janeiro: UFRJ- Fórum de Ciência e Cultura, 2000, p. 188-190; d) CADES e sua presença em Minas Gerais. Congresso de Pesquisa e Ensino em História da Educação em Minas Gerais/2003, Uberlândia. Anais do II Congresso de Pesquisa e Ensino em História da Educação em Minas Gerais.

Uberlândia: Editora EDFU/2003; e) Campanha de Aperfeiçoamento e Difusão do Ensino Secundário: uma trajetória bem sucedida? In: MENDONÇA, Ana Waleska e XAVIER, Libânia Nacif (orgs). Por uma política de formação do magistério nacional: INEP/MEC dos anos 1950/1960. Brasília: Instituto Nacional de Estudos e Pesquisas Educacionais Anísio Teixeira, Coleção INEP 70 anos, v. 1, 2008, 260 p.

13) Dicionário de Educadores no Brasil: da Colônia aos dias atuais, realizado de jan./1977 a fev./1999, tendo por objetivos: a) recuperar informações sobre a vida e obra de educadores já falecidos no Brasil, como previsto em uma das linhas de pesquisa do PROEDES, centrada na análise da construção do pensamento educacional brasileiro; b) servir como referência ao estudo do pensamento educacional brasileiro, identificando suas origens, matrizes e expressões objetivadas na história da educação. O projeto foi desenvolvido por Maria de Lourdes de A. Favero e Jader de Medeiros Britto (com Bolsa de Pesquisador da FAPERJ). Contando com a importante contribuição dos autores dos verbetes. A $1^{\text {a }}$ edição foi publicada com 74 verbetes, pela Editora UFRJ, em convênio com MEC-INEP, 1999, 496 p. Os Coordenadores do Dicionário receberam do Conselho Nacional de Educação (CNE), reunido em sessão plenária de março/2000, voto de louvor pelo trabalho de organização da obra. Em 2002, foi lançada a $2^{a}$ edição ampliada, com 144 verbetes, pela Editora UFRJ com o INEP, 2002, 1008 p. Entre as obras produzidas no PROEDES, este Dicionário merece especial destaque, por ser objeto de consulta por muitos estudiosos e pesquisadores da área de educação e áreas afins.

14) A Universidade do Distrito Federal (1935-1939): um projeto além de seu tempo. Pesquisa coordenada por Maria de Lourdes de A. Favero e Sonia de Castro Lopes, sendo o relatório final publicado em uma coletânea de livro pela Editora Liber Livro, Brasília, em 2009, mantendo o título do projeto. Trata-se de trabalho empreendido por integrantes do grupo de pesquisa sobre a Universidade do Distrito Federal com o apoio do CNPq. Como está registrada na Apresentação do livro: "Esta coletânea analisa a experiência da Universidade do Distrito Federal, que funcionou na cidade do Rio de Janeiro de 1935 a 1939”. É um trabalho realizado por membros do grupo de pesquisa "A Universidade do Distrito Federal (UDF): centro de cultura e de produção de saber”, com o apoio do CNPq. O livro contém seis capítulos e cinco anexos referentes à UDF, com um total de 256 p. Os seis capítulos foram produzidos pelos pesquisadores: a) Maria de Lourdes de A. 
Favero, "A UDF: uma concepção alternativa de Universidade"; b) Sonia de Casto Lopes, "A Escola de Educação como eixo integrador da Universidade"; c) Diana Couto Pinto, "A Escola de Filosofia e Letras: um projeto em vir-a-ser"; d) Bruno Alves Dassie, "A contribuição de Euclides Roxo para a formação do professor de Matemática da UDF" (Esse autor não participou do projeto de pesquisa, mas seu estudo foi elaborado com base nas pesquisas realizadas por ele para a tese de doutorado);.e) Sonia de Castro Lopes, "A formação do professor-especialista: propostas curriculares para o curso de História da UDF" e f) Jader de Medeiros Britto, "Expressão de Humanismo na experiência da UDF".

15) Durmeval Trigueiro Mendes e a questão da universidade: 1960-1980, desenvolvido de mar./2003 a fev./2006, tendo por objetivos: a) analisar questões e propostas contidas nos textos do pensador e educador sobre universidade, no período de 1960 a 1980 e que poderiam servir de referência para o estudo da universidade no país, naquele período e nos dias atuais; b) analisar as ideias e questões mais recorrentes em seus escritos, como: concepção de educação e universidade; ensino e pesquisa e extensão universitária; autonomia e governo da universidade; expansão e acesso ao ensino superior; pós-graduação; qualidade e quantidade em educação.

Integraram o projeto: Maria de Lourdes de A. Favero, Helena Ibiapina Lima e Jader de Medeiros Britto. Como as duas professoras trabalhavam também, nesse período, no Mestrado em Educação da Universidade Católica de Petrópolis (UCP), o projeto foi desenvolvido paralelamente no Mestrado em Educação dessa Universidade, como desdobramento de disciplinas, dando origem a dissertações e comunicações em congressos e seminários.

Dos trabalhos apresentados em congressos e encontros acadêmicocientíficos temos: a) Maria de Lourdes de A. Favero: "Durmeval Trigueiro Mendes e seu legado à pós-graduação em educação no Brasil”, apresentado no VII Congreso Iberoamericano de Historia de la Educación Latinoamericana. Anais do VII Congreso. Quito/Ecuador, Universidad Andina Simón Bolivar, 2005; b) "Durmeval Trigueiro Mendes, ideias e atuação", apresentado no VI Congresso Luso-Brasileiro de História da Educação. Anais do VI Congresso Luso-Brasileiro de História da Educação. Uberlândia: Universidade Federal de Uberlândia, 2006, v. 1 p. 20-35. Como produção dos bolsistas de Iniciação Científica temos: a) Renato de Oliveira Flores. "Durmeval Trigueiro Mendes e seu legado à Educação"; b) Alexandre Corner de Moraes, "Durmeval Trigueiro Mendes: qualidade/quantidade e a expansão do ensino superior", trabalhos apresentados na I Jornada de Iniciação Científica da Universidade Católica de 
Petrópolis/UCP, em 2003; c) Vinicius Neves Sabadim, "Durmeval Trigueiro Mendes: concepção de universidade e de educador", apresentado na III Jornada de Iniciação Científica, realizada na UCP, em 2005.

Além das bolsas de Iniciação Científica e Apoio Técnico, o CNPq manteve, no período, uma bolsa de Produtividade em Pesquisa para a Coordenadora do Projeto, mais o Adicional de Bancada. Como resultados da pesquisa, destacam-se as publicações: a) Livro: Durmeval Trigueiro Mendes. Ensaios sobre Educação e Universidade, organizado por Maria de Lourdes de A. Favero e Jader de Medeiros Britto. Brasília: MEC/INEP, 2006, 218 p.; b) Capítulos de livros: Maria de Lourdes de A. Favero. "Durmeval Trigueiro Mendes e seu pensamento prospectivo". In: Walter Garcia (Org.) Educadores Brasileiros do Século XX. Brasília: Editora Plano, 2002, v.1, p.93-113; Helena Ibiapina Lima, "A Atualidade de Durmeval Trigueiro Mendes em algumas questões do ensino superior". In: Maurício Castanheira e Leila Ramos (Orgs.). Educação e conhecimento: novas leituras para antigos problemas. Rio de Janeiro: Papel Virtual Editora, 2003, p.157-168.

16) Arquivo Permanente da ANPEd - Associação Nacional de PósGraduação e Pesquisa em Educação, que está sob a guarda do PROEDES, contendo documentos desde as primeiras reuniões que ocorreram desde 1976, para analisar sua criação, até 2015 , quando se realizou sua $37^{a}$ Reunião Nacional, em out./2015, seguida da posse da Diretoria e do Conselho Fiscal, em 08/12/2015, constituindo-se em importante fonte de estudos para a área de educação em geral e para a pós-graduação em especial.

Segundo critério adotado pela Direção da ANPEd, sua Secretaria Geral mudava de sede a cada dois anos, ou a cada quatro anos, em caso de reeleição da diretoria. Em decorrência, o arquivo de sua documentação não tinha endereço fixo, o que preocupava permanentemente os associados, especialmente aqueles que sabiam da importância do acervo. Em fins de 1999, eleita uma Diretoria que passou a ter sede novamente no Rio de Janeiro, ficou decidido que o acervo da Associação deveria ficar sob a guarda de um órgão que trabalhasse com arquivos relativos à educação brasileira. A escolha se definiu pelo PROEDES/ FE/UFRJ, em virtude do trabalho que desenvolvia e por ser reconhecido, na área de educação e áreas afins, como um centro de referência em educação brasileira. Consequentemente, na mudança realizada do acervo de São Paulo para o Rio de Janeiro, em 2004, a documentação foi separada em dois arquivos: o arquivo corrente, reunindo documentos em tramitação ou que tinham a ver com as funções das Diretorias eleitas e, em especial da Secretaria, necessários a seu funcionamento; e o arquivo permanente, contendo documentos a serem guardados em caráter definitivo, em função de seu valor ou significado para a história da Associação. 
Embora o trabalho tenha sido iniciado em 2004, apenas em 07/12/2015 a UFRJ e a ANPEd celebraram um acordo de cooperação técnica, visando à preservação dos documentos no PROEDES e o acesso aos pesquisadores interessados. A existência e a organização deste Arquivo justificam-se por duas razões. A primeira refere-se à própria memória da instituição e de seus atores, representada pelos documentos referentes às reuniões científicas, anuais e nacionais realizadas, que compreende conferências e trabalhos apresentados, atas de assembleias, documentos produzidos nessas reuniões; procedimentos relativos à seleção de trabalhos, comunicações e pôsteres; listagens de pesquisadores que participaram de diversas instâncias no empenho de estruturar a Associação; dados sobre educação no Brasil, reunidos em trabalhos efetuados pela entidade e produzidos em encontros regionais de pesquisa; discussões sobre avaliação da educação; participação e contribuição de pesquisadores brasileiros e estrangeiros no processo da educação nacional. A segunda relaciona-se à discussão de temáticas de interesse da pós-graduação e da pesquisa na área da educação, mesmo indo além de sua própria área, uma vez que a ANPEd, nas reuniões, nos seminários dos grupos de trabalho, em publicações, vem aprofundando essas discussões. Um bom exemplo é o conjunto de documentos sobre a avaliação da pós-graduação, o financiamento da pesquisa e a formação de professores e pesquisadores.

O trabalho com este Arquivo teve como uma de suas preocupações associar memória e história, a fim de que se possa preservar o passado dessa entidade acadêmico-científica e, ao mesmo tempo, proporcionar subsídios a pesquisadores empenhados em desenvolver estudos e investigações sobre a educação brasileira.

A organização de um arquivo permanente é trabalho demorado e paciente, exigindo a participação de equipe composta por pesquisadores, auxiliares de pesquisa, bolsistas de iniciação científica, além de arquivista com experiência na área. Apesar da carência de pessoal e da falta de recursos financeiros, o trabalho de organização e avaliação deste arquivo foi realizado ao longo de mais de dez anos. Teve início em 2004, com a primeira separação das fontes documentais que se encontravam em caixas e pacotes misturados, num total estimado, naquele momento, em cerca de 20 mil documentos. A separação das fontes documentais e a higienização preliminar (retirada de adesivos, etiquetas, clipes, grampos e outros corpos estranhos às fontes documentais), foi uma fase demorada pelo estado em que se encontravam os documentos e por se dispor apenas de uma auxiliar de pesquisa, em tempo parcial, gratificada como bolsista da ANPEd. De mar./2008 a ago./2012, essa auxiliar passou a atuar como assistente de pesquisa, por haver terminado o mestrado em educação, recebendo uma bolsa de Apoio Técnico concedida pela ANPEd, por intermédio da Fundação José Bonifácio da UFRJ. 
Em 2008, o projeto ganhou impulso com auxílio financeiro da FAPERJ, que possibilitou a aquisição de equipamentos (computador, scanner, impressora) e material de consumo (pastas suspensas, caixas-arquivo, papel alcalino para a preservação e guarda dos documentos, cartuchos para impressora etc.), além de armários da Securit para guarda e preservação dos documentos.

Para a classificação e organização dos documentos foi utilizada a NOBRADE - Norma Brasileira de Descrição Arquivística, que prevê a anotação das seguintes informações: sigla do país, instituição custodiadora, unidade, subunidade, fundo, série, subsérie, número da pasta e número do documento. Essa descrição documental é muito importante na organização de um arquivo permanente, pois facilita o acesso às informações nele contidas. De acordo com a NOBRADE, são estes os campos do Inventário definidos para o processo de descrição: Código de Referência, Tipologia Documental, Autor, Data, Dimensões e Suporte, Observações.

Após a separação e exame preliminar das fontes documentais que integravam o acervo, foi elaborado um plano estrutural do Arquivo, organizando-o em séries. A análise de cada documento mostra em qual série e subsérie do plano estrutural deverá ser incluído, indicando a seguir a definição de tais séries. Observa-se que não são contadas as duplicatas, embora esses documentos fiquem guardados. O Arquivo foi organizado nas seguintes séries e subséries.

$1^{a}$ Série - Documentos Institucionais, abrangendo duas subséries: Correspondência e Administração. A subsérie Correspondência contém documentos desde 1976 até 2015, que remontam à primeira proposta de criação da ANPEd em 1976. A subsérie Administração contém anotações de reuniões das diretorias, atas das primeiras reuniões, atas da eleição, posse das Diretorias e do Conselho Fiscal, Estatutos da ANPEd, agendas e pautas de reuniões, relatórios de atividades desenvolvidas pela ANPEd.

$2^{a}$ Série - Reuniões Científicas, Anuais e Nacionais, abrange documentos desde a $1^{a}$ reunião, realizada em 1978 e duas em 1979, designadas "reuniões científicas". Da $4^{a}$ reunião nacional realizada em 1981, até a 35a ocorrida em 2013, receberam a designação de "reuniões anuais". A partir da 36a realizada em 2013, passaram a ser designadas "reuniões nacionais".

$3^{a}$ Série - Grupos de Trabalho (GT) e Grupos de Estudo (GE), desdobrada em subséries para contemplar os diversos Grupos de Trabalho e Grupos de Estudo da ANPEd.

$4^{a}$ Série - Fórum Nacional de Coordenadores de Programas de PósGraduação em Educação, abrangendo relatórios produzidos em reuniões dos coordenadores dos Programas de Pós-Graduação em Educação e documentos a eles referentes. 
$5^{\text {a }}$ Série - Seminários, encontros regionais de pesquisa e demais eventos realizados com a participação e o apoio da ANPEd.

6 a Série - Conferências Brasileiras de Educação (CBEs): I CBE realizada de 31/03 a 03/04/1980, na PUC/SP; II CBE, realizada de 10 a 13/06/1982, na UFMG; III CBE, realizada de 12 a 15/10/1984, na UFF; IV CBE, realizada de 02 a 05/09/1986, na Universidade Católica de Goiás; V CBE, realizada de 02 a 05/08/1988, na UnB e a VI CBE, realizada de 03 a 06/09/1991, na USP.

$7^{a}$ Série - Instituições Oficiais, abrangendo documentos referentes à relação da ANPEd com órgãos da União, particularmente CAPES, CNPq, FINEP e INEP, e também com diversas fundações de amparo à pesquisa dos Estados.

$8^{a}$ Série - Instituições Acadêmico-Científicas, composta de espécies documentais referentes à relação da ANPEd com a SBPC e instituições acadêmicocientíficas congêneres, assim como os diversos fóruns dos quais participa.

$9^{a}$ Série - Documentos Contábeis e Financeiros, contendo elementos contábeis, especialmente balanços anuais, com respectivos pareceres do Conselho Fiscal; recibos e listagens da contribuição de sócios individuais e institucionais (1978-1995); diários de operações realizadas; documentos trabalhistas; impostos e contribuições pagas pela ANPEd e outros. A maior parte desses documentos tem mais de vinte anos.

$10^{a}$ Série - Publicações, incluindo a Revista Brasileira de Educação (RBE), Boletins e Cadernos ANPEd, Catálogos de Teses e Dissertações, livros e outras publicações produzidas pelos Grupos de Trabalho ou decorrentes de estudos e pesquisas realizadas pela ANPEd em função de contratos e convênios.

Desde a fase de organização, o arquivo está aberto ao público para consulta, sendo procurado por pesquisadores do Rio de Janeiro e de outros estados, principalmente a Série Reuniões Científicas, Anuais e Nacionais.

O trabalho de sua organização foi realizado por Maria de Lourdes de A. Favero, Coordenadora; Osmar Favero, Consultor; Jader de Medeiros Britto, Colaborador; Maurício Girão Plata, Apoio Técnico; Auxiliares de Pesquisa: Cláudia Araújo dos Santos Bayert e Márcia Cristina Rocha Gomes, além de bolsistas de Iniciação Científica, ao longo do período.

O conjunto dos documentos classificados atualmente atinge cerca de 10 mil referências, número inferior às primeiras estimativas do acervo. Isso ocorreu, primeiro, pela existência de grande número de duplicatas e cópias (guardadas, mas não contadas); pela exclusão dos trabalhos recusados, contendo os pareceres; pela eliminação de muitos documentos em cópia fax praticamente em branco e sem nenhum valor, ou que não diziam respeito à ANPEd. A ordenação das fontes 
documentais, sua análise e a conclusão da classificação estendeu-se até final de 2016. O trabalho final foi salvo em um DVD, entregue à Diretoria da ANPEd, para divulgação.

\section{FINALIZANDO}

Neste trabalho, procuramos apresentar a experiência da construção coletiva de um Centro de Pesquisa e Documentação numa Universidade que, apesar de dificuldades, tornou-se viável. Espaço que se institucionalizou gradualmente, com promissoras perspectivas de construir o conhecimento sobre a história de instituições educacionais e científicas no país e seus atores, bem como sobre o pensamento educacional brasileiro. Todavia, temos presente que se trata de processo em permanente construção, resultante de condições históricas e institucionais, parte de uma realidade concreta. Realidade essa que não pode ser tomada como pronta e acabada. Se é um processo em construção, como tal, precisa ser continuamente analisado e repensado por aqueles que continuam trabalhando e o produzindo.

Parafraseando Tiago de Mello, podemos dizer que depois de quase trinta anos de trabalho, em um espaço de pesquisa e documentação como o PROEDES, não se tem um caminho novo, o que se tem de novo é a forma de caminhar. Aprendemos a cada dia que nos convém ter consciência de que não se pode caminhar sozinho (Mello, 1966, p. 59).

\section{REFERÊNCIAS}

BRASIL. Conselho Nacional de Arquivos. NOBRADE: Norma Brasileira de Descrição Arquivística. Rio de Janeiro: Arquivo Nacional, 2006.

CARR, Edward H. Que é História? Rio de Janeiro: Paz e Terra, 1978.

CARTA DE ALFORRIA da Baronesa de Guanabara, concedendo liberdade à escrava Cypriana. Rio de Janeiro, $1^{\circ}$ de março de 1878. Arquivo Asylo dos Meninos Desvalidos. PROEDES/FE/UFRJ.

LE GOFF, Jacques. História e memória. $2^{\mathrm{a}}$ ed. Campinas: Editora UNICAMP, 1992.

MELLO, Thiago de. Faz escuro, mas eu canto. A canção do amor amado. Rio de N. Editora Civilização Brasileira, 1966. 
NEVES, Margarida de Souza. O bordado de um tempo: a história de Esaú e Jacó.

Revista Tempo Brasileiro. Rio de Janeiro, n. 81, p. 32-42, abr./jun. 1985.

\section{Maria de Lourdes de Albuquerque Fávero}

Livre-docente em Educação pela Pontifícia Universidade Católica do Rio de Janeiro. É professora aposentada da Faculdade de Educação da Universidade Federal do Rio de Janeiro (UFRJ). Fundadora e pesquisadora do PROEDES, cujas origens datam de 1987, e sua Coordenadora até junho de 2009. Em dezembro de 2014 recebeu moção de louvor da Congregação da Faculdade de Educação da UFRJ e passou a exercer a função de pesquisadora honorária, até o final de 2016.

Recebido em 03 de janeiro de 2020. Aceito em 02 de fevereiro de 2020. 